\title{
Interfering Role of ER $\alpha$ on Adiponectin Action in Breast Cancer
}

\section{OPEN ACCESS}

Edited by:

Tania Fiaschi,

University of Florence, Italy

Reviewed by:

Andrea Morandi,

University of Florence, Italy

Adana A. M. Llanos,

The State University of New Jersey,

United States

*Correspondence:

Loredana Mauro

loredana.mauro@unical.it

Sebastiano Ando

sebastiano.ando@unical.it

†These authors share first authorship

₹These authors share senior authorship

Specialty section:

This article was submitted to Translational Endocrinology,

a section of the journal

Frontiers in Endocrinology

Received: 25 September 2019

Accepted: 31 January 2020

Published: 18 February 2020

Citation:

Naimo GD, Gelsomino L, Catalano S,

Mauro $L$ and Andò $S$ (2020) Interfering

Role of ER $\alpha$ on Adiponectin Action in

Breast Cancer.

Front. Endocrinol. 11:66.

doi: 10.3389/fendo.2020.00066

\section{Giuseppina Daniela Naimo ${ }^{1 \dagger}$, Luca Gelsomino ${ }^{1 \dagger}$, Stefania Catalano ${ }^{1}$, Loredana Mauro ${ }^{1 * \neq}$ and Sebastiano Andò ${ }^{1,2 * \neq}$}

${ }^{1}$ Department of Pharmacy, Health and Nutritional Sciences, University of Calabria, Arcavacata, Italy, ${ }^{2}$ Health Center, University of Calabria, Arcavacata, Italy

Obesity is characterized by an excess of adipose tissue, due to adipocyte hypertrophy and hyperplasia. Adipose tissue is an endocrine organ producing many bioactive molecules, called adipokines. During obesity, dysfunctional adipocytes alter adipokine secretion, contributing to pathophysiology of obesity-associated diseases, including metabolic syndrome, type 2-diabetes, cardiovascular diseases and many types of malignancies. Circulating adiponectin levels are inversely correlated with BMI, thus adiponectin concentrations are lower in obese than normal-weight subjects. Many clinical investigations highlight that low adiponectin levels represent a serious risk factor in breast carcinogenesis, and are associated with the development of more aggressive phenotype. A large-scale meta-analysis suggests that BMl was positively associated with breast cancer mortality in women with ER $\alpha$-positive disease, regardless menopausal status. This suggests the importance of estrogen signaling contribution in breast tumorigenesis of obese patients. It has been largely demonstrated that adiponectin exerts a protective role in ER $\alpha$-negative cells, promoting anti-proliferative and pro-apoptotic effects, while controversial data have been reported in ER $\alpha$-positive cells. Indeed, emerging data provide evidences that adiponectin in obese patients behave as growth factor in ER $\alpha$-positive breast cancer cells. This addresses how ER $\alpha$ signaling interference may enhance the potential inhibitory threshold of adiponectin in ER $\alpha$-positive cells. Thus, we may reasonably speculate that the relatively low adiponectin concentrations could be still not adequate to elicit, in ER $\alpha$-positive breast cancer cells, the same inhibitory effects observed in ER $\alpha$-negative cells. In the present review we will focus on the molecular mechanisms through which adiponectin affects breast cancer cell behavior in relationship to $\mathrm{ER} \alpha$ expression.

\section{Keywords: breast cancer, obesity, adiponectin, estrogen receptor alpha, adipose tissue}

\section{INTRODUCTION}

Overweight and obesity are characterized by increased fat tissue accumulation. The World Health Organization classified as overweight people, subjects with body mass index (BMI) $>25 \mathrm{~kg} / \mathrm{m}^{2}$, and as obese, people with BMI $>30 \mathrm{~kg} / \mathrm{m}^{2}$ (30.0-34.9, grade I; 35.0-39.9, grade II; and 40, grade III). These pathological conditions are known to have a global impact on public health and are getting substantial attention worldwide, being recognized as the epidemic of the twenty-first century. Overweight/obese patients have nearly doubled since 1980s and nowadays represent a third of the world population and by the year 2030 will reach the $57.8 \%(1,2)$. Specifically, the prevalence 
of overweight individuals was $38.5 \%$ in men and $39.4 \%$ in women, and the proportion of obese patients was $10.1 \%$ in men and $14.8 \%$ in women. These data underline a higher incidence in women (3). Moreover, obesity is considered a comorbid condition, determining a severe health public concern since it is associated with several diseases, such as diabetes, coronary artery disorders, hypertension, kidney illness, disability and poor mental health deeply negatively impacting quality of life, work productivity and healthcare expenses (4-7). In addition, several clinical trials described a correlation between excess of body weight and the development and progression of many cancers, especially in post-menopausal breast tumors (8-17). Nevertheless, most studies evidenced that the effect of obesity on pre-menopausal or post-menopausal breast cancer risk are closely related to the disease subtypes, exhibiting ER $\alpha$ expression (9). However, obesity is associated with to poor breast cancer outcomes irrespective of menopausal status (9).

Breast carcinoma is a complex and heterogeneous disease, whose development and progression depends on various genetic predispositions and several established factors (age, sex, family history, gene mutations, reproductive factors). It is now clear that modifiable factors, such as alcohol drinking, smoking, physical inactivity and overweight, also have an important role in breast tumorigenesis $(13,18-22)$. Here, we will focus on the molecular mechanisms by which obesity impact breast cancer pathogenesis. Particularly, we will outline the role of adiponectin in this type of cancer discussing epidemiological, in vivo and in vitro studies.

\section{Obesity and Breast Cancer Epidemiology}

In 2018 GLOBOCAN reported that worldwide breast cancer is the most diagnosed malignancy (2.1 million new cases) and represents the second cause of death in women $(626,679$ death accounting for $13 \%$ of cancer-related death). Several studies have reported the association between obesity, increased BMI and risk of breast cancer recurrence and mortality, showing important differences across menopausal status and disease subtypes. Nevertheless, in obese pre-menopausal women the reported data are still uncertain and controversial (23). It is fully demonstrated that obese post-menopausal women have

Abbreviations: BMI, Body Mass Index; ER, Estrogen Receptor; PR, Progesterone Receptor; IGF-1, Insulin-like Growth Factor; TME, Tumor Microenvironment; hATT-CMs, human Adipose Tissue explants of breast Tumors; hATN-CMs, human Adipose Tissue explants of Normal breast tissue; FAs, Fatty Acids; MMPs, Matrix Metalloproteinase; TNF- $\alpha$, Tumor Necrosis Factor $\alpha$; CLS, Crown-Like Structure; IL-6, Interleukin-6; IL-8, Interleukin-8; CCL2, C-C Motif Chemokine Ligand 2; CCL5, C-C Motif Chemokine Ligand 5; JAK2, Janus Kinase 2; STAT3, Signal Transducer and Activator of Transcription 3; MAPK, Mitogen-Activated Protein Kinase; PI3K, Phosphatidylinositol 3-Kinases; LMW, Low Molecular Weight; MMW, Medium Molecular Weight; HMW, High Molecular Weight; gAd, globular Adiponectin; fAd, full-length Adiponectin; AdipoR1, Adiponectin Receptor 1; AdipoR2, Adiponectin Receptor 2; CD1, Cyclin D1; AMPK, 5 Adenosine Monophosphate-activated Protein Kinase; TSC1, Tuberous Sclerosis 1; TSC2, Tuberous Sclerosis 2; mTOR, mammalian Target Of Rapamycin; RNAseq, RNA sequencing; MMTVPyV-mT, Mouse Mammary Tumor Virus-Polyoma middle Tumor-antigen; WT, Wild Type; VEGF, Vascular Epidermal Growth Factor; $E_{2}$, Estradiol; APPL1, Adaptor protein, Phosphotyrosine interacting with PH domain and Leucine zipper 1; LKB1, Liver Kinase B1; CRTC2, CREB Regulated Transcription Coactivator 2. a higher chance of developing breast cancer with a more advanced disease (larger tumor size, lymph-node positivity, regional/distance stage after diagnosis) compared with their normal counterpart (24). The correlation between breast cancer risk and obesity differs based on ER expression and menopausal status. Indeed, the development of estrogen receptor (ER) and progesterone receptor (PR)-positive breast cancer (24-28) markedly occurs in post-menopausal women, while the incidence of ER-negative tumors is more frequent in premenopausal patients (9). Besides, obese condition is considered a risk factor since overweight survivor breast cancer patients may develop a second primary malignancy, such as endometrial or colorectal neoplasia (29). Excess body weight may also negatively interfere in early diagnosis, therapeutic management, standard oncologic intervention and care of patients. In fact, in the obese population medical imaging and image-guided may be difficult to accomplish, while after surgical intervention probably may experience medical complications (30-34) and worst clinical outcome due to the dose-limited absorption of the conventional chemotherapy drugs $(35,36)$. Epidemiological studies welldescribed the role of obesity in impacting breast cancer treatment and prognosis but the biological mechanisms that link these pathological conditions are complex to elucidate. It has been demonstrated that the hyperactivation of Insulin/IGF-1 pathway due to "diabesity" condition (obesity concomitant with insulin resistance, hyperinsulinemia and/or hyperglycemia) mediates breast cancer progression (37-39). Obesity is also related to elevate circulating estrogen levels, as a result of increased aromatase activity in adipose tissue, chronically blunted inflammatory status and deregulated adipokine secretion, that bridge excess body weight condition and breast cancer.

\section{Breast Cancer, Tumor Microenvironment and Adipose Tissue}

Breast cancer is an intricate "rogue" organ wherein cancer cells surrounded by extracellular matrix and stromal cells create a complex tumor microenvironment (TME). Tumor cells and vital components of TME, such as fibroblasts and myofibroblasts, neuroendocrine, adipose, immune, inflammatory, and endothelial cells, interact via complex and dynamic network (40). Adipocytes are key components in the stroma of breast carcinoma. Indeed, adipose tissue is now recognized as a bioactive endocrine organ. Fletcher et al. demonstrated profound changes in the proteomic profile between the conditioned media obtained from human adipose tissue explants of breast tumors (hATT-CMs) compared to human adipose tissue explants of normal breast tissue (hATN$\mathrm{CMs}$ ). Most of the proteins differentially expressed were involved in important biological processes, including immune response and metabolism, and the treatment with hATT-CMs induces proliferation, adhesion and migration of breast cancer cells (4143). In obese condition, adipocytes are hypertrophic, due to the increased accumulation of intracellular triglyceride stores caused by the energy imbalance, and hyperplastic, since their number augments in this pathology (44). Obese patients showed an excess of pathological and dysfunctional adipose tissue that leads to an enrichment of several biologically active factors (hormones, 
lipid metabolites, inflammatory cytokines, and adipokines) in the TME $(45,46)$. Hypertrophic and hyperplastic adipocytes through their metabolic substrates, such as both saturated and unsaturated fatty acids (FAs) and matrix metalloproteinase (MMPs), regulate breast cancer biology. FAs are stored as lipid droplet in the adipose tissue and their release, induced by highfat diet and obese status, may contribute to angiogenesis and inflammation, key steps of tumor development and progression (47). Mostly, FAs can activate toll-like receptor 4 and NF$\mathrm{kB} / \mathrm{TNF}-\alpha$ signaling. This contributes to create a low chronic inflammatory status of TME responsible for the recruitment of macrophages that encircle damaged, dying or dead adipocytes forming a crown-like structure (CLS) in adipose stromal breast tissue. Macrophage CLSs negatively influence breast cancer recurrence and survival (48-50). Adipocytes also through the direct release of several cytokines (IL-6, IL8, IFN $\mathrm{I}_{\curlyvee}$-inducible protein 10) and chemokines (CCL2 and CCL5) and the secretion of FAs, MMP-9, MMP-11, and MMP-13, may induce chronic inflammation, tumor initiation and metastatic burden in breast cancers. Moreover, adipocytes produce molecules, defined as "released hormones," including estrogens and adipokines. In post-menopausal obese patients, the elevated level of estrogens, produced by aromatase highly expressed in adipocytes, activates $\mathrm{ER} \alpha$, promoting breast cancer cell growth and progression (47). Furthermore, changes in adipokines profile, due to the altered fat distribution and function, is one of the main features in obese state. Particularly, obese patients showed elevated serum leptin levels while adiponectin concentrations are decreased. It has been fully elucidated the role of leptin in breast cancer biology. Several studies reported that this adipokine secreted by adipocytes, tumor cells and cancer associated fibroblasts, induces the activation of several signaling pathways (i.e., JAK2/STAT3, MAPK, and PI3K/Akt) involved in the control of cell proliferation, differentiation, survival, migration, and invasion (51). Different epidemiological studies strongly support the inverse correlation between adiponectin and breast cancer, attributing to this adipokine a protective role. For instance, new evidences addressed its mechanistic involvement in breast tumor progression when present at low circulating levels (52-54).

\section{Adiponectin and Its Functions}

Adiponectin is mainly secreted by adipose tissue and in limited quantities by fat brown, salivary gland, cardiac tissue, cerebrospinal fluid, bone marrow (55-58). Adiponectin is synthetized as a single subunit with a primary sequence of 244 aminoacids divided into four domains: at $\mathrm{N}$-terminus a signal peptide, followed by a short hyper-variable region, a collagenous region containing 22 Gly-X-Y repeats, and at Cterminus a globular domain that interacts with the receptors $(39,59-62)$. Once produced, the monomeric form of adiponectin undergoes to post-transcriptional modifications that allow the formation of disulfide-linked oligomers composed of trimers (Low Molecular Weight, LMW), hexamers (Medium Molecular Weight, MMW), and multimers (High Molecular Weight, HMW), detectable in the circulation (63-66). Furthermore, this adipokine exists in human plasma in a globular form (gAd), consisting only of the C-terminus domain, produced by a proteolytic cleavage of the full-length protein (fAd) at aminoacid $110(60,67)$ (Figure 1). Adiponectin exerts different biological functions, such as regulation of glucose uptake and insulin sensitivity, and stimulation of fatty acid oxidation (68-72). Moreover, adiponectin decreases the pro-inflammatory cytokines production (TNF- $\alpha$ and IL-6), prevents monocytes migration, affecting vascular endothelium, and mediates anti-atherogenic actions through the inhibition of subendothelial cholesterol accumulation (73-75). The response to adiponectin is related to the structural heterogeneity of serum adipokine isoforms and to the target tissues (70). Indeed, adiponectin activates two main seven-transmembrane receptors, Adiponectin Receptor 1 (AdipoR1) and 2 (AdipoR2). They are detected in almost every tissue, but generally with a different expression ratio and affinity for the adipokine oligomers $(55,62,76,77)$. Physiologically, adiponectin contributes to the $0.05 \%$ of total proteins present in the systemic circulation, with a concentration ranging from 3 to $30 \mu \mathrm{g} / \mathrm{ml}$, depending on hormonal, inflammatory, pharmacological and dietary factors $(70,78,79)$. Adiponectin plasma levels are reduced in obese compared to normalweight subjects, negatively correlating with $\mathrm{BMI}(39,80)$. The mechanisms responsible for this down-regulation have not yet been fully elucidated. It has been formulated several hypotheses, some of which are related to the chronic low inflammatory state of adipose tissue and to the adipocytes dysfunction that characterize obesity condition. Particularly, it has been speculated that the hypoadiponectinemia in obesity may be due to the increased production of pro-inflammatory cytokines, such as TNF- $\alpha$ and IL-6, or to a negative feedback of the adipokine on its own production and that of its receptors $(39,81,82)$. Low adiponectin levels have also been linked to an increased risk of developing type 2 diabetes, metabolic syndrome, insulin resistance, hypertension, cardiovascular disease, and different malignancies, including breast cancer (59).

\section{Adiponectin and Breast Cancer}

Pre-clinical studies with different experimental approached highlight the role of adiponectin on angiogenesis along breast tumorigenesis $(83,84)$. Using the transgenic mouse mammary tumor virus-polyoma middle tumor-antigen (MMTVPyV$\mathrm{mT}$ ) model of mammary cancer, it has been reported that adiponectin acts as a pro-angiogenic factor contributing to tumor vascularization and consequently to tumor growth and progression. Denzel et al. introducing adiponectin null mutation in MMTVPyV-mT (APN-KO) mice, a model closely related to human disease, found a delay in tumor onset, reduction in tumor growth kinetics and increased survival over wild type (WT) mice used as controls (83). Accordingly, another group reported that the chronic adiponectin depletion, after the use of an anti-mouse adiponectin monoclonal antibody, showed consistent and similar results obtained in APN-KO mice. On the other hand, a direct involvement of this adipokine in the angiogenic processes raised by the evidences that mice exposed to a series of adiponectin injection showed increased mRNA levels of the vascular epidermal growth factor (VEGF) release, well-known angiogenic factors, involved in blood vessel formation (84). Many epidemiological studied confirmed a 


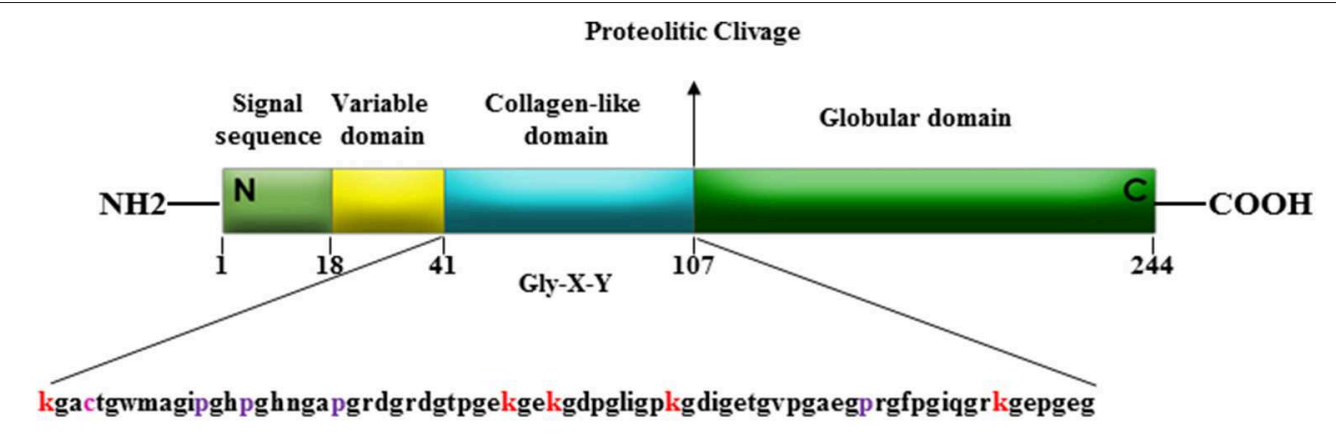

Proteolitic Clivage

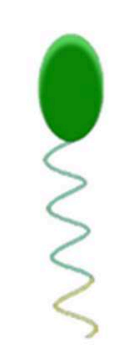

Monomer

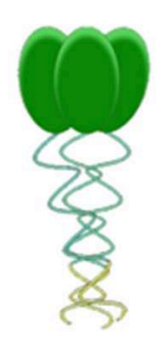

Trimer
(LMW)

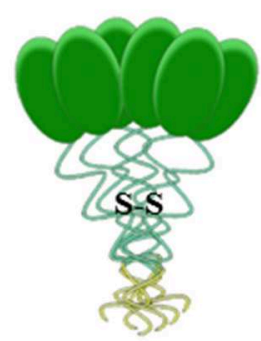

Examer (MMW)

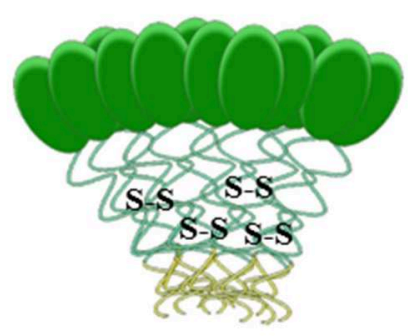

Multimer
(HMW)

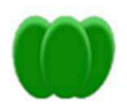

Globular

FIGURE 1 | Domains and molecular structure of adiponectin. Adiponectin is a 244 amino acid protein mainly synthetized by adipocytes as a single subunit including a $\mathrm{N}$-terminal signal sequence, a variable region, a collagen-like domain and a globular domain in C-terminus. Adiponectin before secretion undergoes to oligomerization to form trimers (LMW), hexamers (MMW), and multimers (HMW). Adiponectin is also present in plasma in a globular isoform (gAd) generated by a proteolytic cleavage at amino acid 110 of the full-length protein $(\mathrm{fAd})$.

positive correlation between hypoadiponectinemia and obesityrelated breast cancer. Several case-control studies associated low circulating levels of adiponectin with an increased breast cancer risk and the development of a more aggressive phenotype in post-menopausal women, regardless of BMI, leptin, and IGF-I levels (85-92). Interestingly, this relationship has been observed prevalently in ER/PR-negative cancer (93). Furthermore, Oh et al. reported an inverse association between ER/PR-negative breast cancer recurrence and reduced serum adiponectin levels (93). This may be due to a cross-talk between adipose tissuederived hormones, estrogens, progesterone and insulin signaling pathway that influenced adiponectin secretion (70). Nevertheless, a recent meta-analysis highlighted an increased incidence of intraepithelial breast tumor development and a higher risk of invasiveness in pre-menopausal women (94). Particularly, low adiponectin levels may favor tumor growth and progression, promoting fatty acid and protein synthesis or supporting the enhanced production of insulin, IGF-1, and pro-inflammatory cytokines (70). However, accumulating data demonstrated that the role of adiponectin in breast carcinogenesis, especially in post-menopausal women, could be closely dependent on cell types (60). Specifically, in vitro and in vivo studies evidenced a dichotomic effect on breast tumor growth and progression in relationship to $\mathrm{ER} \alpha$ status $(52-54,95)$.

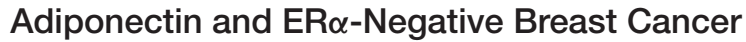

Due to the importance of adiponectin in the regulation of breast cancer cell growth and proliferation, many investigations have attempted to elucidate the role of adiponectin accordingly to $\mathrm{ER} \alpha$ expression. Several experimental models have documented the anti-proliferative and pro-apoptotic effects exerted by adiponectin in ER $\alpha$-negative breast cancer cells (53, 96-102). Particularly, many evidences proved that even low adiponectin concentrations counteract breast carcinogenesis mediating the increase of Bax, p21, p53 expression and inducing cell cycle arrest, at G0/G1 phase, through the down-regulation of cyclin D1 (CD1) $(54,103)$. Moreover, adiponectin is able to upregulate phosphorylation of AMPK, promoting TSC1/TSC2 complex formation, which in turn inhibits mTOR activation, and thus ER $\alpha$-negative cell growth (52). Further investigations demonstrated the adiponectin negative action on lamellopodia formation, preventing cell migration and invasion $(98,104,105)$. Additionally, a very recent RNA sequencing analysis (RNA-seq) highlighted the down-regulation of genes involved in G1/S and G2/M transition of cell cycle, including CD1, cyclin A2 and cyclin-dependent kinase 1, and CKAP2 and RRM1, implicated in the microtubule assembly and DNA replication during $\mathrm{S}$ phase, in adiponectin-treated MDA-MB-231 cells (52, 106-108). From the same analysis emerged the increased expression of genes 
involved in the cell cycle inhibition, such as TGFBR1, IGFBP3, and MAGED1, and genes sustaining apoptosis and cell death, among which $F A S, B I K, B I D$, and caspases $(52,109-111)$.

\section{Adiponectin and ER $\alpha$-Positive Breast Cancer}

Several authors reported a protective role of adiponectin in ER $\alpha$-positive breast cancer cells $(86,100,105,112-116)$, but divergent actions of the adipokine are emerging on this specific breast cancer subtype $(52-54,117,118)$. Some studies described the inhibitory action of adiponectin on breast cancer cell growth by the up-regulation of p53, p21 and Bax and/or the reduced expression of $\mathrm{c}-\mathrm{myc}$, cyclin $\mathrm{D}$, and Bcl-2 levels $(78,119,120)$. Furthermore, it has been reported that fulllength adiponectin induces apoptosis and cell death, promoting cytotoxic autophagy through the modulation of the LKB1AMPK-ULK axis in breast cancer cells (121). Thus, based on the latter findings it is reasonable to speculate that prospectively the combined treatment of adiponectin with current chemotherapy drugs may reduce their effective dose lowering the side effects (121).

Recently, many evidences sustained the existence of a direct cross talk between adiponectin and ER signaling in breast cancer cells. In this concern, Pfeiler et al. demonstrated that estradiol $\left(E_{2}\right)$ treatment led to a down-regulation of AdipoR1 expression (117). Moreover, they showed that full-length adiponectin enhanced the $\mathrm{E}_{2}$-induced proliferation rate in $\mathrm{ER} \alpha$-positive MCF-7 breast cancer cells (117). Thus, the authors reported that the cross-talk between $\mathrm{E}_{2}$ and adiponectin affects breast cancer growth, highlighting an opposite action of adiponectin to that one generally assumed on human breast cancer cell behavior (117).

Several reports described that adiponectin contributes to breast tumor evolution stimulating growth and migration of ER $\alpha$-positive cells. Particularly, recent evidences elucidated several potential mechanisms through which globular adiponectin acts as a stimulatory factor in ER $\alpha$-positive breast cancer (52-54). Mauro et al. demonstrated a dichotomic effect of adiponectin in ER $\alpha$-positive and $\mathrm{ER} \alpha$-negative cells (53). They showed that adiponectin at 1 and $5 \mu \mathrm{g} / \mathrm{ml}$, mimicking circulating levels in obese patients, exerted opposite effects between the two cell models. Adiponectin increased proliferation and cell growth in ER $\alpha$-positive cells and these pro-tumor properties were completely abrogated either by ER $\alpha$ pharmacological inhibition (ICI 182,780), or by silencing its expression. Mechanistically, they found that adiponectin impacts $\mathrm{ER} \alpha$ function at both nongenomic and genomic levels. Adiponectin treatment in MCF-7 cells increased the complex interaction between AdipoR1/APPL1 and $\mathrm{mER} / \mathrm{IGF} 1 \mathrm{R} / \mathrm{c}$-Src that leads to MAPK activation, sustaining cell growth. Moreover, through MAPK signaling, adiponectin was also able to trans-activates $\mathrm{ER} \alpha$, as demonstrated by its ability to increase XETL luciferase activity and the expression of classical $\mathrm{ER} \alpha$-responsive genes (pS2, Cathepsin D) (53). In summary, they proposed that $\mathrm{ER} \alpha$ expression negatively interferes with the anti-proliferative effect mediated by adiponectin on breast

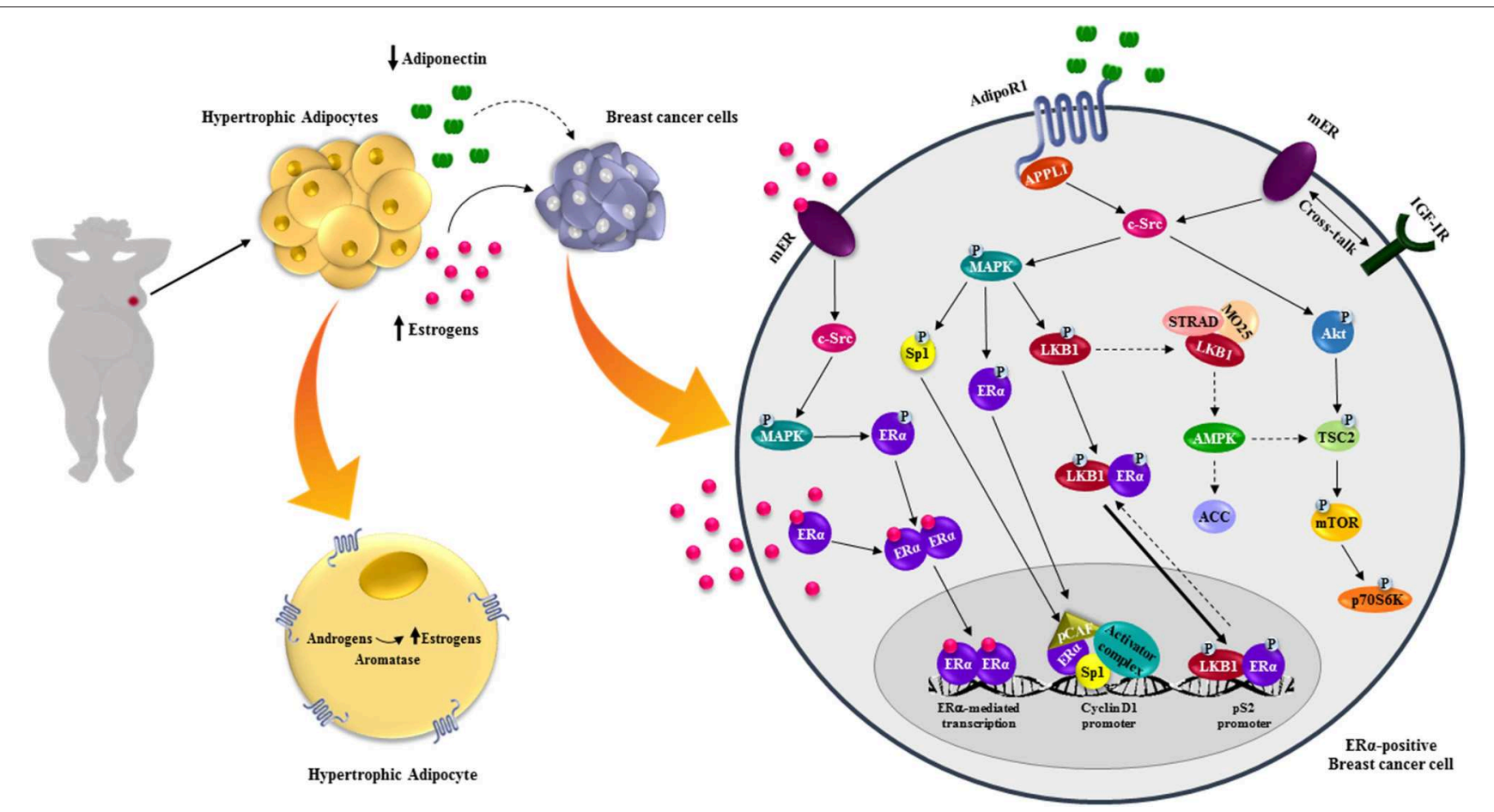

FIGURE 2 | Effects of adiponectin on ER $\alpha$-positive breast cancer cells. Obesity is characterized by hypertrophic adipocytes, which release high levels of estrogens, due to the increased aromatase activity, and low adiponectin concentrations. Estrogens bind and stimulate estrogen receptors action at both genomic and non-genomic levels. In ER $\alpha$-positive breast cancer cells low adiponectin levels activate different intracellular signaling pathways promoting breast tumor growth. 
cancer cell growth (53). Subsequently, in vivo experiments demonstrated an increased breast tumor growth in mice receiving MCF-7 cells pre-treated with adiponectin, concomitant with a marked increased expression of Ki67. All these finding were corroborated by experimental evidences reporting an up-regulation of CD1 expression in adiponectin-treated ER $\alpha$ positive cells (54). Recently, it has been demonstrated that, upon adiponectin exposure, $\mathrm{ER} \alpha / \mathrm{LKB} 1$ interaction increased both in the cytosol and in the nucleus. All this contribute to impair LKB1 capability to activate AMPK and in such way weakening its consolidate role as onco-suppressor (52). Moreover, adiponectin enhanced Akt-induced TSC2 phosphorylation in MCF-7 cells, enabling mTOR to activate p70S6K. Notably, the absence of ER $\alpha$, using a specific siRNA or the ICI 182,780, totally abrogated the adiponectin-mediated effects on LKB1/AMPK/mTOR signaling pathway (52). These data demonstrated the importance of $\mathrm{ER} \alpha$ in regulating adiponectin actions in breast cancer cells (52). Furthermore, adiponectin increased ER $\alpha$ transcriptional activity only in the presence of LKB1, suggesting that LKB1 may be recruited as $\mathrm{ER} \alpha$ co-activator (Figure 2). Finally, it has been shown that adiponectin exerts its effects in ER $\alpha$-positive breast cancer cells in relation to its concentration. Indeed, $5 \mu \mathrm{g} / \mathrm{ml}$ adiponectin, simulating obese condition, induced cell proliferation and tumor growth, which was no longer noticeable at $30 \mu \mathrm{g} / \mathrm{ml}$, corresponding to normal weight (52). RNA-seq fully elucidated how adiponectin doses ( 5 and $30 \mu \mathrm{g} / \mathrm{ml}$ ) differentially influenced several important signaling pathways, modulating the expression of genes that control cell proliferation, cell cycle progression, apoptosis, cell death, necrosis and fatty acid metabolism. It has been reported that ER $\alpha$ expression switched the energy balance of breast cancer upon adiponectin exposure leading to a lipogenic more aggressive phenotype (52). Thus, these findings revealed a novel role of adiponectin in $\mathrm{ER} \alpha$-positive breast cancer, contributing to elucidate its controversial and previously reported dichotomic effects in this tumor setting. Adiponectin/AMPK axis also influences the circulating estrogens bioavailability through modulating aromatase activity in the breast. Brown et al. demonstrated that AMPK could phosphorylate CRTC2, one of the CREBregulated transcription co-activators, blocking its nuclear translocation. At low adiponectin concentrations, not adequate to fuel AMPK activation, the non-phosphorylated CRCT2 binds CREB inducing transcription of target genes, including aromatase, in breast adipose tissues, contributing to tumor cell proliferation. Notably, this is a reasonable aspect linking low adiponectin levels with breast cancer growth and progression in obesity (122).

However, Swami et al. investigated the beneficial effects of dietary vitamin D supplementation on the enhanced estrogen synthesis in the breast microenvironment during obesity (123). Particularly, they observed, concomitantly with an enhanced AdipoR1 and adiponectin mRNA expression, a decrease of aromatase levels in mammary tumors of obese mice (123). Moreover, the authors evidenced that vitamin D could directly reduce aromatase synthesis by increasing the expression of LKB1, which drives AMPK phosphorylation in breast cancer cells. Overall, these data suggest that vitamin D may counteract the obesity-induced breast cancer growth, increasing adiponectin signaling and reducing local estrogen synthesis (123).

Since estrogens may influence adiponectin levels, it is worth to evaluate the possible link existing between adiponectin serum concentration and aromatase enzymatic activity in women with breast cancer. Recent preliminary clinical data evidenced that, in a small cohort of post-menopausal patients diagnosed with $\mathrm{ER} \alpha$-positive breast cancer and receiving aromatase inhibitors as adjuvant hormonal therapy, a short-term estrogen depletion did not affect adiponectin serum levels. Anyway, the limited clinical data available indicate that further efforts will be needed to provide translational relevance to these observations (124).

\section{CONCLUSIONS}

Breast carcinoma is a complex and heterogeneous disease, whose development and progression depend not only on genetic predispositions. Indeed, it has been well-demonstrated that overweight and obese status deeply impact both breast cancer risk and behavior of the disease. An altered adipokine secretion, wherein adiponectin plasma levels dramatically decreased, mostly characterizes the obesity-related pathological expansion of adipose tissue. Although adiponectin is a well-recognized anticancer agent especially in breast cancer, recent studies suggested that the low adiponectin concentrations could amplify ER signaling, contributing to breast tumor development and progression. This led us to rethink adiponectin role in this neoplasia as a potential therapeutic tools. Prospectively, all new therapeutic strategies aimed to potentiate adiponectin actions (i.e., increasing its circulating levels or the binding to its own receptor) should be carefully assessed separately in ER $\alpha$-positive and ER $\alpha$-negative breast cancers.

\section{AUTHOR CONTRIBUTIONS}

GN and LG reviewed the literature, prepared the manuscript, wrote, edited, and prepared the figures. SC, LM, and SA revised and provided the critical consideration for the manuscript, design, and editing. All authors have read and approved the final version of this manuscript agreed to be accountable for all aspects of the work and consent for publication.

\section{FUNDING}

This work was supported by the Associazione Italiana Ricerca sul Cancro (AIRC; IG-18602 and IG-21414) and the Progetti di Ricerca di Interesse Nazionale-Ministero Istruzione Università e Ricerca (Grant 2015B7M39T_001 and 2017EKMFTN_001). 


\section{REFERENCES}

1. Kelly $\mathrm{T}$, Yang $\mathrm{W}$, Chen CS, Reynolds $\mathrm{K}$, He J. Global burden of obesity in 2005 and projections to 2030. Int J Obesity. (2008) 32:1431. doi: $10.1038 /$ ijo.2008.102

2. Bray F, Ferlay J, Soerjomataram I, Siegel RL, Torre LA, Jemal A. Global cancer statistics 2018: GLOBOCAN estimates of incidence and mortality worldwide for 36 cancers in 185 countries. CA Cancer J Clin. (2018) 68:394424. doi: 10.3322 /caac. 21492

3. Risk N. Factor collaboration (NCD-RisC). trends in adult body-mass index in 200 countries from 1975 to 2014: a pooled analysis of 1698 populationbased measurement studies with 19.2 million participants. Lancet. (2016) 387:1377-96. doi: 10.1016/S0140-6736(16)30054-X

4. Lu Y, Hajifathalian K, Ezzati M, Woodward M, Rimm E, Danaei G. Global burden of metabolic risk factors for chronic diseases collaboration (BMI Mediated Effects). metabolic mediators of the effects of body-mass index, overweight, and obesity on coronary heart disease and stroke: a pooled analysis of 97 prospective cohorts with 1.8 million participants. Lancet. (2014) 383:970-83. doi: 10.1016/S0140-6736(13)61836-X

5. Di Angelantonio E, Bhupathiraju SN, Wormser D, Gao P, Kaptoge S, de Gonzalez $\mathrm{AB}$, et al. Body-mass index and all-cause mortality: individualparticipant-data meta-analysis of 239 prospective studies in four continents. Lancet. (2016) 388:776-86. doi: 10.1016/S0140-6736(16)30175-1

6. Kim DD, Basu A. Estimating the medical care costs of obesity in the United States: systematic review, meta-analysis, and empirical analysis. Value Health. (2016) 19:602-13. doi: 10.1016/j.jval.2016.02.008

7. von Lengerke T, Krauth C. Economic costs of adult obesity: a review of recent European studies with a focus on subgroup-specific costs. Maturitas. (2011) 69:220-9. doi: 10.1016/j.maturitas.2011.04.005

8. Schottenfeld D, Beebe-Dimmer JL, Buffler PA, Omenn GS. Current perspective on the global and United States cancer burden attributable to lifestyle and environmental risk factors. Ann Rev Public Health. (2013) 34:97-117. doi: 10.1146/annurev-publhealth-031912-114350

9. Picon-Ruiz M, Morata-Tarifa C, Valle-Goffin JJ, Friedman ER, Slingerland JM. Obesity and adverse breast cancer risk and outcome: mechanistic insights and strategies for intervention. CA Cancer J Clin. (2017) 67:37897. doi: 10.3322/caac. 21405

10. Engin AB, Engin A. Obesity and Lipotoxicity. Cham: Springer (2017).

11. Kolb R, Phan L, Borcherding N, Liu Y, Yuan F, Janowski AM, et al. Obesity-associated NLRC4 inflammasome activation drives breast cancer progression. Nat Commun. (2016) 7:13007. doi: 10.1038/ncomms13007

12. Chan D, Vieira A, Aune D, Bandera E, Greenwood D, McTiernan A, et al. Body mass index and survival in women with breast cancer-systematic literature review and meta-analysis of 82 follow-up studies. Ann Oncol. (2014) 25:1901-14. doi: 10.1093/annonc/mdu042

13. Lahart IM, Metsios GS, Nevill AM, Carmichael AR. Physical activity, risk of death and recurrence in breast cancer survivors: a systematic review and meta-analysis of epidemiological studies. Acta Oncol. (2015) 54:63554. doi: 10.3109/0284186X.2014.998275

14. Duggan C, de Dieu Tapsoba J, Wang CY, Campbell KL, Foster-Schubert $\mathrm{K}$, Gross MD, et al. Dietary weight loss, exercise, and oxidative stress in postmenopausal women: a randomized controlled trial. Cancer Prevent Res. (2016) 9:835-43. doi: 10.1158/1940-6207.CAPR-16-0163

15. Chu DT, Nguyet NTM, Dinh TC, Lien NVT, Nguyen KH, Ngoc VTN, et al. An update on physical health and economic consequences of overweight and obesity. Diabetes Metab Syndr. (2018) 12:1095100. doi: $10.1016 /$ j.dsx.2018.05.004

16. Ferlay J, Soerjomataram I, Dikshit R, Eser S, Mathers C, Rebelo M, et al. Cancer incidence and mortality worldwide: sources, methods and major patterns in GLOBOCAN 2012. Int J Cancer. (2015) 136:E359E86. doi: $10.1002 / \mathrm{ijc} .29210$

17. Winkels RM, Sturgeon KM, Kallan MJ, Dean LT, Zhang Z, Evangelisti $M$, et al. The women in steady exercise research (wiser) survivor trial: the innovative transdisciplinary design of a randomized controlled trial of exercise and weight-loss interventions among breast cancer survivors with lymphedema. Contemp Clin Trials. (2017) 61:63-72. doi: 10.1016/j.cct.2017.07.017
18. Danaei G, Vander Hoorn S, Lopez AD, Murray CJ, Ezzati M, group CRAc. Causes of cancer in the world: comparative risk assessment of nine behavioural and environmental risk factors. Lancet. (2005) 366:178493. doi: 10.1016/S0140-6736(05)67725-2

19. McDonald JA, Goyal A, Terry MB. Alcohol intake and breast cancer risk: weighing the overall evidence. Current Breast Cancer Rep. (2013) 5:20821. doi: 10.1007/s12609-013-0114-z

20. Mullooly M, Khodr ZG, Dallal CM, Nyante SJ, Sherman ME, Falk R, et al. Epidemiologic risk factors for in situ and invasive breast cancers among postmenopausal women in the National Institutes of Health-AARP diet and health study. Am J Epidemiol. (2017) 186:1329-40. doi: 10.1093/aje/kwx206

21. Ordóñez-Mena JM, Schöttker B, Mons U, Jenab M, Freisling H, Buenode-Mesquita B, et al. Quantification of the smoking-associated cancer risk with rate advancement periods: meta-analysis of individual participant data from cohorts of the CHANCES consortium. BMC Med. (2016) 14:62. doi: 10.1186/s12916-016-0607-5

22. O'Sullivan CC, Loprinzi CL, Haddad TC, Updates in the evaluation and management of breast cancer. Mayo Clin Proc. (2018) 93:794807. doi: 10.1016/j.mayocp.2018.03.025

23. Laudisio D, Muscogiuri G, Barrea L, Savastano S, Colao A. Obesity and breast cancer in premenopausal women: current evidence and future perspectives. Eur J Obstet Gynecol Reprod Biol. (2018) 230:21721. doi: 10.1016/j.ejogrb.2018.03.050

24. Neuhouser ML, Aragaki AK, Prentice RL, Manson JE, Chlebowski R, Carty $\mathrm{CL}$, et al. Overweight, obesity, and postmenopausal invasive breast cancer risk: a secondary analysis of the women's health initiative randomized clinical trials. JAMA Oncol. (2015) 1:611-21. doi: 10.1001/jamaoncol.2015.1546

25. White AJ, Nichols HB, Bradshaw PT, Sandler DP. Overall and central adiposity and breast cancer risk in the Sister Study. Cancer. (2015) 121:37008. doi: $10.1002 / \mathrm{cncr} .29552$

26. Munsell MF, Sprague BL, Berry DA, Chisholm G, Trentham-Dietz A. Body mass index and breast cancer risk according to postmenopausal estrogenprogestin use and hormone receptor status. Epidemiol Rev. (2014) 36:11436. doi: 10.1093/epirev/mxt010

27. Cotterchio M, Kreiger N, Theis B, Sloan M, Bahl S. Hormonal factors and the risk of breast cancer according to estrogen-and progesterone-receptor subgroup. Cancer Epidemiol Prevent Biomark. (2003) 12:1053-60.

28. Bandera EV, Chandran U, Hong CC, Troester MA, Bethea TN, Adams-Campbell LL, et al. Obesity, body fat distribution, and risk of breast cancer subtypes in African American women participating in the AMBER Consortium. Breast Cancer Res Treat. (2015) 150:655-66. doi: 10.1007/s10549-015-3353-z

29. Druesne-Pecollo N, Touvier M, Barrandon E, Chan DS, Norat T, Zelek L, et al. Excess body weight and second primary cancer risk after breast cancer: a systematic review and meta-analysis of prospective studies. Breast Cancer Res Treat. (2012) 135:647-54. doi: 10.1007/s10549-012-2187-1

30. Fischer JP, Cleveland EC, Nelson JA, Kovach SJ, Serletti JM, Wu LC, et al. Breast reconstruction in the morbidly obese patient: assessment of 30-day complications using the 2005 to 2010 national surgical quality improvement Program data sets. Plastic Reconstr Surg. (2013) 132:75061. doi: 10.1097/PRS.0b013e31829fe33c

31. Fischer JP, Nelson JA, Kovach SJ, Serletti JM, Wu LC, Kanchwala S. Impact of obesity on outcomes in breast reconstruction: analysis of 15,937 patients from the ACS-NSQIP datasets. J Am College Surg. (2013) 217:65664. doi: 10.1016/j.jamcollsurg.2013.03.031

32. Fischer JP, Wes AM, Tuggle CT, Wu LC. Venous thromboembolism risk in mastectomy and immediate breast reconstruction: analysis of the 2005 to 2011 american college of surgeons national surgical quality improvement program data sets. Plastic Reconstr Surg. (2014) 133:263e-73e. doi: 10.1097/01.prs.0000438062.53914.22

33. Jeevan R, Browne J, Pereira J, Caddy C, Sheppard C, van der Meulen J, et al. Socioeconomic deprivation and inpatient complication rates following mastectomy and breast reconstruction surgery. Brit J Surg. (2015) 102:106470. doi: 10.1002/bjs. 9847

34. DiSipio T, Rye S, Newman B, Hayes S. Incidence of unilateral arm lymphoedema after breast cancer: a systematic review and meta-analysis. Lancet Oncol. (2013) 14:500-15. doi: 10.1016/S1470-2045(13)70076-7 
35. Griggs JJ, Sorbero ME, Lyman GH. Undertreatment of obese women receiving breast cancer chemotherapy. Archiv Intern Med. (2005) 165:126773. doi: 10.1001/archinte.165.11.1267

36. Argolo DF, Hudis CA, Iyengar NM. The impact of obesity on breast cancer. Curr Oncol Rep. (2018) 20:47. doi: 10.1007/s11912-018-0688-8

37. Gunter MJ, Hoover DR, Yu H, Wassertheil-Smoller S, Rohan TE, Manson JE, et al. Insulin, insulin-like growth factor-I, and risk of breast cancer in postmenopausal women. J Natl Cancer Inst. (2009) 101:4860. doi: 10.1093/jnci/djn415

38. Christopoulos PF, Msaouel P, Koutsilieris M. The role of the insulinlike growth factor-1 system in breast cancer. Mol Cancer. (2015) 14:43. doi: 10.1186/s12943-015-0291-7

39. Mauro L, Naimo GD, Ricchio E, Panno ML, Andò S. Cross-talk between adiponectin and IGF-IR in breast cancer. Front Oncol. (2015) 5:157. doi: 10.3389/fonc.2015.00157

40. Balkwill FR, Capasso M, Hagemann T. The tumor microenvironment at a glance. J Cell Sci. (2012) 25:5591-6. doi: 10.1242/jcs.116392

41. Creydt VP, Sacca PA, Tesone AJ, Vidal L, Calvo JC. Adipocyte differentiation influences the proliferation and migration of normal and tumoral breast epithelial cells. Mol Med Rep. (2010) 3:433-9. doi: 10.3892/mmr_00000276

42. Fletcher SJ, Sacca PA, Pistone-Creydt M, Coló FA, Serra MF, Santino FE, et al. Human breast adipose tissue: characterization of factors that change during tumor progression in human breast cancer. J Exp Clin Cancer Res. (2017) 36:26. doi: 10.1186/s13046-017-0494-4

43. Fletcher SJ, Hapon MB, Callegari EA, Crosbie ML, Santiso N, Ursino A, et al. Comparative proteomics of soluble factors secreted by human breast adipose tissue from tumor and normal breast. Oncotarget. (2018) 9:31007. doi: 10.18632/oncotarget.25749

44. de Ferranti S, Mozaffarian D. The perfect storm: obesity, adipocyte dysfunction, and metabolic consequences. Clin Chem. (2008) 54:94555. doi: 10.1373/clinchem.2007.100156

45. Matafome P, Santos-Silva D, Sena C, Seica R. Common mechanisms of dysfunctional adipose tissue and obesity-related cancers. Diabetes Metab Res Rev. (2013) 29:285-95. doi: 10.1002/dmrr.2395

46. Choi J, Cha YJ, Koo JS. Adipocyte biology in breast cancer: From silent bystander to active facilitator. Prog Lipid Res. (2017) 69:1120. doi: 10.1016/j.plipres.2017.11.002

47. Chu DT, Phuong TNT, Tien NLB, Tran DK, Nguyen TT, Thanh VV, et al. The effects of adipocytes on the regulation of breast cancer in the tumor microenvironment: an update. Cells. (2019) 8:857. doi: 10.3390/cells8080857

48. Koru-Sengul T, Santander AM, Miao F, Sanchez LG, Jorda M, Glück $S$, et al. Breast cancers from black women exhibit higher numbers of immunosuppressive macrophages with proliferative activity and of crown-like structures associated with lower survival compared to nonblack Latinas and Caucasians. Breast Cancer Res Treat. (2016) 158:11326. doi: 10.1007/s10549-016-3847-3

49. Lamkanfi M, Dixit VM. Mechanisms and functions of inflammasomes. Cell. (2014) 157:1013-22. doi: 10.1016/j.cell.2014.04.007

50. Yin Z, Deng T, Peterson LE, Yu R, Lin J, Hamilton DJ, et al. Transcriptome analysis of human adipocytes implicates the NOD-like receptor pathway in obesity-induced adipose inflammation. Mol Cell Endocrinol. (2014) 394:807. doi: 10.1016/j.mce.2014.06.018

51. Andò S, Gelsomino L, Panza S, Giordano C, Bonofiglio D, Barone I, et al. Obesity, leptin and breast cancer: epidemiological evidence and proposed mechanisms. Cancers. (2019) 11:62. doi: 10.3390/cancers11010062

52. Mauro L, Naimo GD, Gelsomino L, Malivindi R, Bruno L, Pellegrino M, et al. Uncoupling effects of estrogen receptor $\alpha$ on LKB1/AMPK interaction upon adiponectin exposure in breast cancer. FASEB J. (2018) 32:434355. doi: 10.1096/fj.201701315R.

53. Mauro L, Pellegrino M, De Amicis F, Ricchio E, Giordano F, Rizza P, et al. Evidences that estrogen receptor $\alpha$ interferes with adiponectin effects on breast cancer cell growth. Cell Cycle. (2014) 13:553-64. doi: 10.4161/cc.27455

54. Mauro L, Pellegrino M, Giordano F, Ricchio E, Rizza P, De Amicis F, et al. Estrogen receptor- $\alpha$ drives adiponectin effects on cyclin D1 expression in breast cancer cells. FASEB J. (2015) 29:2150-60. doi: 10.1096/fj.14-262808

55. Brochu-Gaudreau K, Rehfeldt C, Blouin R, Bordignon V, Murphy BD, Palin MF. Adiponectin action from head to toe. Endocrine. (2010) 37:1132. doi: 10.1007/s12020-009-9278-8
56. Fujimoto N, Matsuo N, Sumiyoshi H, Yamaguchi K, Saikawa T, Yoshimatsu $\mathrm{H}$, et al. Adiponectin is expressed in the brown adipose tissue and surrounding immature tissues in mouse embryos. Biochim Biophys Acta. (2005) 1731:1-12. doi: 10.1016/j.bbaexp.2005.06.013

57. Katsiougiannis S, Kapsogeorgou EK, Manoussakis MN, Skopouli FN. Salivary gland epithelial cells: a new source of the immunoregulatory hormone adiponectin. Arthritis Rheum. (2006) 54:2295-9. doi: 10.1002/art.21944

58. Kusminski C, McTernan P, Schraw T, Kos K, O’hare J, Ahima $\mathrm{R}$, et al. Adiponectin complexes in human cerebrospinal fluid: distinct complex distribution from serum. Diabetologia. (2007) 50:634-42. doi: 10.1007/s00125-006-0577-9

59. Gelsomino L, Naimo GD, Catalano S, Mauro L, Andò S. The emerging role of adiponectin in female malignancies. Int J Mol Sci. (2019) 20:2127. doi: 10.3390/ijms20092127

60. Panno ML, Naimo GD, Spina E, Andò S, Mauro L. Different molecular signaling sustaining adiponectin action in breast cancer. Curr Opin Pharmacol. (2016) 31:1-7. doi: 10.1016/j.coph.2016.08.001

61. Simpson F, Whitehead JP. Adiponectin-it's all about the modifications. Int J Biochem Cell Biol. (2010) 42:785-8. doi: 10.1016/j.biocel.2009.12.021

62. Yamauchi T, Kamon J, Ito Y, Tsuchida A, Yokomizo T, Kita S, et al. Cloning of adiponectin receptors that mediate antidiabetic metabolic effects. Nature. (2003) 423:762. doi: 10.1038/nature01705

63. Tsao TS, Tomas E, Murrey HE, Hug C, Lee DH, Ruderman NB, et al. Role of disulfide bonds in Acrp30/adiponectin structure and signaling specificity: different oligomers activate different signal transduction pathways. J Biol Chem. (2003) 278:50810-7. doi: 10.1074/jbc.M309469200

64. Tsao TS, Murrey HE, Hug C, Lee DH, Lodish HF. Oligomerization statedependent activation of NF- $\kappa \mathrm{B}$ signaling pathway by adipocyte complementrelated protein of $30 \mathrm{kDa}$ (Acrp30). J Biol Chem. (2002) 277:2935962. doi: 10.1074/jbc.C200312200

65. Wang Y, Xu A, Knight C, Xu LY, Cooper GJ. Hydroxylation and glycosylation of the four conserved lysine residues in the collagenous domain of adiponectin potential role in the modulation of its insulinsensitizing activity. J Biol Chem. (2002) 277:19521-9. doi: 10.1074/jbc.M2006 01200

66. Wang Y, Lam KS, Chan L, Chan KW, Lam JB, Lam MC, et al. Posttranslational modifications of the four conserved lysine residues within the collagenous domain of adiponectin are required for the formation of its high molecular weight oligomeric complex. J Biol Chem. (2006) 281:16391400. doi: 10.1074/jbc.M513907200

67. Waki H, Yamauchi T, Kamon J, Kita S, Ito Y, Hada Y, et al. Generation of globular fragment of adiponectin by leukocyte elastase secreted by monocytic cell line THP-1. Endocrinology. (2005) 146:790-6. doi: 10.1210/en.2004-1096

68. Wang C, Mao X, Wang L, Liu M, Wetzel MD, Guan KL, et al. Adiponectin sensitizes insulin signaling by reducing p70 S6 kinasemediated serine phosphorylation of IRS-1. J Biol Chem. (2007) 282:79916. doi: 10.1074/jbc.M700098200

69. Stefan N, Vozarova B, Funahashi T, Matsuzawa Y, Weyer C, Lindsay RS, et al. Plasma adiponectin concentration is associated with skeletal muscle insulin receptor tyrosine phosphorylation, and low plasma concentration precedes a decrease in whole-body insulin sensitivity in humans. Diabetes. (2002) 51:1884-8. doi: 10.2337/diabetes.51.6.1884

70. Dalamaga M, Diakopoulos KN, Mantzoros CS. The role of adiponectin in cancer: a review of current evidence. Endocr Rev. (2012) 33:54794. doi: 10.1210/er.2011-1015

71. Garaulet M, Hernandez-Morante JJ, de Heredia FP, Tébar FJ. Adiponectin, the controversial hormone. Public Health Nutr. (2007) 10:1145-50. doi: 10.1017/S1368980007000638

72. Yamauchi T, Kamon J, Waki H, Terauchi Y, Kubota N, Hara K, et al. The fat-derived hormone adiponectin reverses insulin resistance associated with both lipoatrophy and obesity. Nat Med. (2001) 7:941. doi: 10.1038/90984

73. Sheikhpour R. The role of adiponectin in breast cancer: the mechanism and action. Basic Clin Cancer Res. (2016) 8:32-7. doi: 10.1371/journal.pone.0073183

74. Lopez-Jaramillo P. The role of adiponectin in cardiometabolic diseases: effects of nutritional interventions-3. J Nutr. (2016) 146:422S-6S. doi: 10.3945/jn.114.202432 
75. Ouchi N, Kihara S, Arita Y, Nishida M, Matsuyama A, Okamoto $\mathrm{Y}$, et al. Adipocyte-derived plasma protein, adiponectin, suppresses lipid accumulation and class A scavenger receptor expression in human monocyte-derived macrophages. Circulation. (2001) 103:1057-63. doi: 10.1161/01.CIR.103.8.1057

76. Kadowaki T, Yamauchi T. Adiponectin and adiponectin receptors. Endocrine Rev. (2005) 26:439-51. doi: 10.1210/er.2005-0005

77. Goldstein BJ, Scalia R. Adiponectin: a novel adipokine linking adipocytes and vascular function. J Clin Endocrinol Metabol. (2004) 89:25638. doi: 10.1210/jc.2004-0518

78. Obeid S, Hebbard L. Role of adiponectin and its receptors in cancer. Cancer Biol Med. (2012) 9:213. doi: 10.7497/j.issn.2095-3941.2012.04.001

79. Chandran M, Phillips SA, Ciaraldi T, Henry RR. Adiponectin: more than just another fat cell hormone? Diabetes Care. (2003) 26:244250. doi: $10.2337 /$ diacare.26.8.2442

80. Galic S, Oakhill JS, Steinberg GR. Adipose tissue as an endocrine organ. $\mathrm{Mol}$ Cell Endocrinol. (2010) 316:129-39. doi: 10.1016/j.mce.2009.08.018

81. Tilg H, Moschen AR. Adipocytokines: mediators linking adipose tissue, inflammation and immunity. Nat Rev Immunol. (2006) 6:772. doi: $10.1038 /$ nri1937

82. Bauche IB, El Mkadem SA, Rezsohazy R, Funahashi T, Maeda N, Miranda LM, et al. Adiponectin downregulates its own production and the expression of its AdipoR2 receptor in transgenic mice. Biochem Biophy Res Commun. (2006) 345:1414-24. doi: 10.1016/j.bbrc.2006.05.033

83. Denzel MS, Hebbard LW, Shostak G, Shapiro L, Cardiff RD, Ranscht B. Adiponectin deficiency limits tumor vascularization in the MMTV-PyVmT mouse model of mammary cancer. Clin Cancer Res. (2009) 15:325664. doi: 10.1158/1078-0432.CCR-08-2661

84. Landskroner-Eiger S, Qian B, Muise ES, Nawrocki AR, Berger JP, Fine EJ, et al. Proangiogenic contribution of adiponectin toward mammary tumor growth in vivo. Clin Cancer Res. (2009) 15:3265-76. doi: 10.1158/1078-0432.CCR-08-2649

85. Dalamaga M, Karmaniolas K, Papadavid E, Pelekanos N, Sotiropoulos G, Lekka A. Elevated serum visfatin/nicotinamide phosphoribosyltransferase levels are associated with risk of postmenopausal breast cancer independently from adiponectin, leptin, and anthropometric and metabolic parameters. Menopause. (2011) 18:1198-204. doi: 10.1097/gme.0b013e31821e21f5

86. Körner A, Pazaitou-Panayiotou K, Kelesidis T, Kelesidis I, Williams CJ, Kaprara A, et al. Total and high-molecular-weight adiponectin in breast cancer: in vitro and in vivo studies. J Clin Endocrinol Metabol. (2007) 92:1041-8. doi: 10.1210/jc.2006-1858

87. Mantzoros C, Petridou E, Dessypris N, Chavelas C, Dalamaga M, Alexe DM, et al. Adiponectin and breast cancer risk. J Clin Endocrinolog Metabol. (2004) 89:1102-7. doi: 10.1210/jc.2003-031804

88. Chen DC, Chung YF, Yeh YT, Chaung HC, Kuo FC, Fu OY, et al. Serum adiponectin and leptin levels in Taiwanese breast cancer patients. Cancer Lett. (2006) 237:109-14. doi: 10.1016/j.canlet.2005. 05.047

89. Hou WK, Xu YX, Ting Y, Zhang L, Zhang WW, Fu CL, et al. Adipocytokines and breast cancer risk. Chinese Med J. (2007) 120:15926. doi: 10.1097/00029330-200709020-00009

90. Miyoshi Y, Funahashi T, Kihara S, Taguchi T, Tamaki Y, Matsuzawa Y, et al. Association of serum adiponectin levels with breast cancer risk. Clin Cancer Res. (2003) 9:5699-704.

91. Shahar S, Salleh RM, Ghazali AR, Koon PB, Mohamud W. Roles of adiposity, lifetime physical activity and serum adiponectin in occurrence of breast cancer among Malaysian women in Klang Valley. Asian Pac J Cancer Prev. (2010) 11:61-6.

92. Tworoger SS, Eliassen AH, Kelesidis T, Colditz GA, Willett WC, Mantzoros CS, et al. Plasma adiponectin concentrations and risk of incident breast cancer. J Clin Endocrinol Metabol. (2007) 92:15106. doi: 10.1210/jc.2006-1975

93. Oh SW, Park CY, Lee ES, Yoon YS, Lee ES, Park SS, et al. Adipokines, insulin resistance, metabolic syndrome, and breast cancer recurrence: a cohort study. Breast Cancer Res. (2011) 13:R34. doi: 10.1186/bcr2856

94. Macis D, Gandini S, Guerrieri-Gonzaga A, Johansson H, Magni P, Ruscica $\mathrm{M}$, et al. Prognostic effect of circulating adiponectin in a randomized $2 \times 2$ trial of low-dose tamoxifen and fenretinide in premenopausal women at risk for breast cancer. J Clin Oncol. (2012) 30:151. doi: 10.1200/JCO.2011.35.2237

95. Alessi DR, Sakamoto K, Bayascas JR. LKB1-dependent signaling pathways. Annu Rev Biochem. (2006) 75:13763. doi: 10.1146/annurev.biochem.75.103004.142702

96. Dos Santos E, Benaitreau D, Dieudonne MN, Leneveu MC, Serazin V, Giudicelli Y, et al. Adiponectin mediates an antiproliferative response in human MDA-MB 231 breast cancer cells. Oncology Rep. (2008) 20:9717. doi: 10.3892/or_00000098

97. Kang JH, Lee YY, Yu BY, Yang BS, Cho KH, Yoon DK, et al. Adiponectin induces growth arrest and apoptosis of MDA-MB-231 breast cancer cell. Arch Pharmacal Res. (2005) 28:1263-9. doi: 10.1007/BF02978210

98. Kim KY, Baek A, Hwang JE, Choi YA, Jeong J, Lee MS, et al. Adiponectin-activated AMPK stimulates dephosphorylation of AKT through protein phosphatase 2A activation. Cancer Res. (2009) 69:4018-26. doi: 10.1158/0008-5472.CAN-08-2641

99. Liu J, Lam JB, Chow KH, Xu A, Lam KS, Moon RT, et al. Adiponectin stimulates Wnt inhibitory factor-1 expression through epigenetic regulations involving the transcription factor specificity protein 1. Carcinogenesis. (2008) 29:2195-202. doi: 10.1093/carcin/bgn194

100. Nakayama S, Miyoshi Y, Ishihara H, Noguchi S. Growth-inhibitory effect of adiponectin via adiponectin receptor 1 on human breast cancer cells through inhibition of S-phase entry without inducing apoptosis. Breast Cancer Res Treat. (2008) 112:405-10. doi: 10.1007/s10549-007-9874-3

101. Taliaferro-Smith L, Nagalingam A, Knight BB, Oberlick E, Saxena NK, Sharma D. Integral role of PTP1B in adiponectin-mediated inhibition of oncogenic actions of leptin in breast carcinogenesis. Neoplasia. (2013) 15:23. doi: $10.1593 /$ neo. 121502

102. Wang Y, Lam JB, Lam KS, Liu J, Lam MC, Hoo RL, et al. Adiponectin modulates the glycogen synthase kinase- $3 \beta / \beta$-catenin signaling pathway and attenuates mammary tumorigenesis of MDA-MB-231 cells in nude mice. Cancer Res. (2006) 66:11462-70. doi: 10.1158/0008-5472.CAN-06-1969

103. Chen X, Wang Y. Adiponectin and breast cancer. Med Oncol. (2011) 28:1288-95. doi: 10.1007/s12032-010-9617-X

104. Man K, Ng KT, Xu A, Cheng Q, Lo CM, Xiao JW, et al. Suppression of liver tumor growth and metastasis by adiponectin in nude mice through inhibition of tumor angiogenesis and downregulation of Rho kinase/IFNinducible protein 10/matrix metalloproteinase 9 signaling. Clinical Cancer Res. (2010) 16:967-77. doi: 10.1158/1078-0432.CCR-09-1487

105. Taliaferro-Smith L, Nagalingam A, Zhong D, Zhou W, Saxena N, Sharma D. $\mathrm{LKB} 1$ is required for adiponectin-mediated modulation of AMPK-S6K axis and inhibition of migration and invasion of breast cancer cells. Oncogene. (2009) 28:2621. doi: 10.1038/onc.2009.129

106. Hong KU, Kim E, Bae CD, Park J. TMAP/CKAP2 is essential for proper chromosome segregation. Cell Cycle. (2009) 8:31424. doi: $10.4161 /$ cc.8.2.7597

107. Kim SH, Park ER, Joo HY, Shen YN, Hong SH, Kim CH, et al. RRM1 maintains centrosomal integrity via CHK1 and CDK1 signaling during replication stress. Cancer Lett. (2014) 346:249-56. doi: 10.1016/j.canlet.2013.12.031

108. Lim S, Kaldis P. Cdks, cyclins and CKIs: roles beyond cell cycle regulation. Development. (2013) 140:3079-93. doi: 10.1242/dev.091744

109. Baxter R. Signalling pathways involved in antiproliferative effects of IGFBP3: a review. Mol Pathol. (2001) 54:145. doi: 10.1136/mp.54.3.145

110. Du Q, Zhang Y, Tian XX, Li Y, Fang WG. MAGE-D1 inhibits proliferation, migration and invasion of human breast cancer cells. Oncol Rep. (2009) 22:659-65. doi: 10.3892/or_00000486

111. Wong RS. Apoptosis in cancer: from pathogenesis to treatment. J Exp Clin Cancer Res. (2011) 30:87. doi: 10.1186/1756-9966-30-87

112. Arditi J, Venihaki M, Karalis K, Chrousos G. Antiproliferative effect of adiponectin on MCF7 breast cancer cells: a potential hormonal link between obesity and cancer. Hormone Metab Res. (2007) 39:913. doi: 10.1055/s-2007-956518

113. Grossmann M, Nkhata K, Mizuno N, Ray A, Cleary M. Effects of adiponectin on breast cancer cell growth and signaling. Br J Cancer. (2008) 98:370. doi: 10.1038/sj.bjc.6604166

114. Jardé T, Caldefie-Chézet F, Goncalves-Mendes N, Mishellany F, Buechler $\mathrm{C}$, Penault-Llorca F, et al. Involvement of adiponectin and leptin in breast 
cancer: clinical and in vitro studies. Endocrine Relat Cancer. (2009) 16:1197210. doi: 10.1677/ERC-09-0043

115. Li G, Cong L, Gasser J, Zhao J, Chen K, Li F. Mechanisms underlying the antiproliferative actions of adiponectin in human breast cancer cells, MCF7dependency on the cAMP/protein kinase-A pathway. Nutr Cancer. (2011) 63:80-8. doi: 10.1080/01635581.2010.516472

116. Nkhata KJ, Ray A, Schuster TF, Grossmann ME, Cleary MP. Effects of adiponectin and leptin co-treatment on human breast cancer cell growth. Oncol Rep. (2009) 21:1611-9. doi: 10.3892/or_00000395

117. Pfeiler GH, Buechler C, Neumeier M, Schäffler A, Schmitz G, Ortmann $\mathrm{O}$, et al. Adiponectin effects on human breast cancer cells are dependent on 17- $\beta$ estradiol. Oncol Rep. (2008) 19:787-93. doi: 10.3892/or.19. 3.787

118. Treeck O, Lattrich C, Juhasz-Boess I, Buchholz S, Pfeiler G, Ortmann O. Adiponectin differentially affects gene expression in human mammary epithelial and breast cancer cells. Br J Cancer. (2008) 99:1246. doi: 10.1038/sj.bjc.6604692

119. Luo Z, Saha AK, Xiang X, Ruderman NB. AMPK, the metabolic syndrome and cancer. Trends Pharmacol Sci. (2005) 26:69-76. doi: 10.1016/j.tips.2004.12.011

120. Dieudonne MN, Bussiere M, Dos Santos E, Leneveu MC, Giudicelli Y, Pecquery R. Adiponectin mediates antiproliferative and apoptotic responses in human MCF7 breast cancer cells. Biochem Biophys Res Commun. (2006) 345:271-9. doi: 10.1016/j.bbrc.2006.04.076

121. Chung SJ, Nagaraju GP, Nagalingam A, Muniraj N, Kuppusamy P, Walker $\mathrm{A}$, et al. ADIPOQ/adiponectin induces cytotoxic autophagy in breast cancer cells through STK11/LKB1-mediated activation of the AMPK-ULK1 axis. Autophagy. (2017) 13:1386-403. doi: 10.1080/15548627.2017.1332565

122. Brown KA, McInnes KJ, Hunger NI, Oakhill JS, Steinberg GR, Simpson ER. Subcellular localization of cyclic AMP-responsive element binding proteinregulated transcription coactivator 2 provides a link between obesity and breast cancer in postmenopausal women. Cancer Res. (2009) 69:53929. doi: 10.1158/0008-5472.CAN-09-0108

123. Swami S, Krishnan AV, Williams J, Aggarwal A, Albertelli MA, Horst RL, et al. Vitamin D mitigates the adverse effects of obesity on breast cancer in mice. Endocr Relat Cancer. (2016) 23:251. doi: 10.1530/ERC-15-0557

124. Pfeiler G, Konigsberg R, Hadji P, Fitzal F, Tea M-KM, Vogl S, et al. The impact of estrogen depletion by aromatase inhibitors on adiponectin serum levels in postmenopausal patients with breast cancer. J. Clin. Oncol. (2013). doi: 10.1200/jco.2013.31.15_suppl.e11601

Conflict of Interest: The authors declare that the research was conducted in the absence of any commercial or financial relationships that could be construed as a potential conflict of interest.

Copyright (c) 2020 Naimo, Gelsomino, Catalano, Mauro and Andò. This is an openaccess article distributed under the terms of the Creative Commons Attribution License (CC BY). The use, distribution or reproduction in other forums is permitted, provided the original author(s) and the copyright owner(s) are credited and that the original publication in this journal is cited, in accordance with accepted academic practice. No use, distribution or reproduction is permitted which does not comply with these terms. 